\title{
Gemcitabine loaded Microbubbles for Targeted Chemo-Sonodynamic Therapy of Pancreatic Cancer
}

Heather Nesbitt ${ }^{1}$, Yingjie Sheng ${ }^{1}$, Sukanta Kamila ${ }^{1}$, Keiran Logan ${ }^{1}$, Keith Thomas ${ }^{1}$, Bridgeen Callan ${ }^{1}$, Mark A Taylor ${ }^{2}$, Mark Love ${ }^{3}$, Declan O'Rourke ${ }^{4}$, Paul Kelly ${ }^{4}$, Estelle Beguin ${ }^{5}$, Eleanor Stride $^{5}$, Anthony P. McHale ${ }^{1}$ and John F. Callan ${ }^{1}$.

1. Biomedical Sciences Research Institute, University of Ulster, Coleraine, Northern Ireland, U.K. BT52 1SA. 2. Department of HPB Surgery, Mater Hospital, Belfast, Northern Ireland, U.K. BT14 6AB. 3. Imaging Centre, The Royal Victoria Hospital, Grosvenor Road, Belfast, Northern Ireland, U.K. BT12 6BA; 4. Department of Pathology, The Royal Victoria Hospital, Grosvenor Road, Belfast, Northern Ireland, U.K. BT12 6BA. 5. Oxford Institute of Biomedical Engineering, University of Oxford, UK, OX3 7DQ

Abstract: Pancreatic cancer remains one of the most lethal forms of cancer with a 10-year survival of $<1 \%$. With little improvement in survival rates observed in the past 40 years, there is a significant need for new treatments or more effective strategies to deliver existing treatments. The antimetabolite gemcitabine (Gem) is the most widely used form of chemotherapy for pancreatic cancer treatment, but is known to produce significant side effects when administered systemically. We have previously demonstrated the benefit of combined chemo-sonodynamic therapy (SDT), delivered using oxygen carrying microbubbles $\left(\mathrm{O}_{2} \mathrm{MB}\right)$, as a targeted treatment for pancreatic cancer in a murine model of the disease. In this manuscript, we report the preparation of a biotin functionalised Gem ligand for attachment to $\mathrm{O}_{2} \mathrm{MBs}\left(\mathrm{O}_{2} \mathrm{MB}-\mathrm{Gem}\right)$. We demonstrate the effectiveness of chemo-sonodynamic therapy following ultrasound-targeted-microbubble-destruction (UTMD) of the $\mathrm{O}_{2} \mathrm{MB}-\mathrm{Gem}$ and a Rose Bengal loaded $\mathrm{O}_{2} \mathrm{MB}\left(\mathrm{O}_{2} \mathrm{MB}-\mathrm{RB}\right)$ as a targeted treatment for pancreatic cancer. Specifically, UTMD using the $\mathrm{O}_{2} \mathrm{MB}-\mathrm{Gem}$ and $\mathrm{O}_{2} \mathrm{MB}-\mathrm{RB}$ conjugates reduced the viability of MIA PaCa-2, PANC-1, BxPC3 and T110299 pancreatic cancer cells by greater than $60 \%(p<0.001)$ and provided significant tumour growth delay $(>80 \%, \mathrm{p}<0.001)$ compared to untreated animals when human xenograft MIA PaCa-2 tumours were treated in SCID mice. The toxicity of the 
$\mathrm{O}_{2} \mathrm{MB}-\mathrm{Gem}$ conjugate was also determined in healthy non-tumour bearing MF1 mice and revealed no evidence of renal or hepatic damage. Therefore, the results presented in this manuscript suggest that chemo-sonodynamic therapy using the $\mathrm{O}_{2} \mathrm{MB}-\mathrm{Gem}$ and $\mathrm{O}_{2} \mathrm{MB}-\mathrm{RB}$ conjugates, is potentially an effective targeted and safe treatment modality for pancreatic cancer.

Keywords: Pancreatic cancer; microbubbles, gemcitabine, ultrasound, sonodynamic therapy, antimetabolite therapy. 
1.0 Introduction: The antimetabolite drug gemcitabine (Gem) is one of the most widely used chemotherapy for pancreatic cancer [1]. While surgical resection remains the only curative treatment for pancreatic cancer, it is only possible in $\sim 20 \%$ of patients who initially present with the disease [2]. The remaining $\sim 80 \%$ of patients are classified as non-resectable at the time of diagnosis with $\sim 40 \%$ having metastatic disease and $\sim 40 \%$ having borderline resectable or locally advanced pancreatic cancer (Borderline resectable pancreatic cancer (BRPC) or locally advanced pancreatic cancer (LAPC)), meaning that while the cancer is still localised to the pancreas, its size or anatomical proximity to major blood vessels makes it difficult for the surgeon to achieve a complete resection [2]. In a bid to improve resection rates, there has been a considerable emphasis in recent years on treating BRPC or LAPC patients with neoadjuvant chemo- or chemo-radiotherapy in an attempt to downstage tumours in advance of surgery [3]. Many of the drug-based treatments for pancreatic cancer involve Gem either as a stand-alone agent or in combination with other chemotherapies / radiotherapy [4]. However, while Gem has dominated the pancreatic cancer chemotherapy market for the past 20 years, the modest overall median survival of 5-7 months and significant off-target toxicity means alternative treatments or more targeted delivery methods would be highly beneficial [5].

Ultrasound targeted microbubble destruction (UTMD) is an emerging field in drug delivery and involves the use of low intensity ultrasound to disrupt microbubbles (MB) at a target site, releasing the attached payloads and encapsulated gas in a localised manner [68]. MBs are lipid or polymer stabilised gas filled particles approved for use as contrast agents in diagnostic ultrasound. At relatively low ultrasound pressures, MBs oscillate continuously, resulting in a strong ultrasound signal that enhances the quality of the diagnostic image. At higher acoustic pressures, inertially driven collapse of the MB leads to rupture and release of any encapsulated material at the target site [8]. An additional benefit of UTMD as a drug delivery strategy is that microbubble cavitation is known to enhance microscale mass transport through impermeable tissue and this has particular relevance when considering payload 
delivery to solid tumours [9]. Indeed, MB cavitation has been attributed to the improved uptake and efficacy of chemotherapy drugs in pre-clinical and clinical studies [10].

We have previously demonstrated the benefit of combined 5-fluorouracil (5-FU) / sonodynamic therapy (SDT) as a potential treatment for pancreatic cancer using oxygen-loaded lipid stabilised microbubbles $\left(\mathrm{O}_{2} \mathrm{MB}\right)$ to deliver both the 5-FU antimetabolite and Rose Bengal SDT sensitiser to pancreatic tumours $[11,12]$. UTMD complements SDT as the ultrasound stimulus also enables activation of the otherwise non-active sensitiser, which in the presence of molecular oxygen, generates toxic quantities of reactive oxygen species (ROS) [13]. Given Gem has superseded 5-FU as the antimetabolite of choice for the treatment of pancreatic cancer, we have developed our MB platform to enable the delivery of Gem to facilitate combination treatment with SDT. Such a targeted combination therapy could find appeal as a neo-adjuvant treatment to reduce tumour burden and ensure a curative R0 resection of the pancreas, or in the setting of unresectable disease, as a palliative therapy to provide improved tumour control with better quality of life.

To this end, we have synthesised a biotin functionalised Gem derivative (compound $\mathbf{4}$, Fig 1) and attached it to the surface of avidin functionalised $\mathrm{O}_{2} \mathrm{MB}$ using the biotin-avidin interaction. The $\mathrm{O}_{2} \mathrm{MB}-\mathrm{Gem}$ conjugate was then used in combination with Rose Bengal functionalised $\mathrm{O}_{2} \mathrm{MB}\left(\mathrm{O}_{2} \mathrm{MB}-\mathrm{RB}\right)$ to facilitate combined chemo-sonodynamic therapy. The efficacy of chemo-sonodynamic therapy treatment using the MB conjugates was determined in vitro, in a panel of pancreatic cancer cells (BxPC3, MIA PaCa-2, PANC-1 and T110299) and in vivo in a MIA PaCa-2 subcutaneous xenograft murine model of the disease. To ensure the combined treatment was safe for potential translation to the clinic, we also conducted a safety study in healthy non-tumour bearing MF-1 mice, to establish the impact of treatment on key blood biochemical markers and liver / kidney histology.

\subsection{Materials \& Methods.}


2.1 Reagents and Materials: 1,2-dibehenoyl-sn-glycero-3-phosphocholine (DBPC) and 1,2distearoyl-sn-glycero-3-phosphoethanolamine- $N$-[methoxy(polyethylene glycol)-2000] (DSPE-PEG(2000)) and DSPE-PEG(2000)-biotin were purchased from Avanti Polar Lipids (Alabaster, Alabama, USA). Oxygen gas was purchased from BOC Industrial Gases UK and perfluorobutane (PFB) was purchased from Apollo Scientific Ltd. Phosphate Buffered Saline (PBS) was purchased from Gibco, Life Technologies, UK. Glycerol and propylene glycol (1 kg, hydrolysed) were purchased from Sigma Aldrich (UK). Optical microscope images were obtained using a Leica DM500 optical microscope. Rose Bengal sodium salt, NHS-biotin, gemcitabine, MTT assay kit, avidin, chloroacetic acid, 4-dimethylaminopyridine (DMAP), hydroxybenzotriazole (HOBt), $N, N^{\prime}$-dicyclohexylcarbodiimide $\quad$ (DCC), anhydrous dimethylformamide (DMF), and ethanol were purchased from Sigma Aldrich (UK) at the highest grade possible. Biotin, di(N-succinimidyl) carbonate and 2-aminoethanol were purchased from Tokyo Chemical Industry UK Ltd. Error was expressed as \pm SEM (standard error of the mean) and statistical comparisons were established using un-paired Student'sttest.

2.2 Synthesis of Biotin-Gem conjugate (4) (2R,3R,5R)-5-(4-amino-2-oxopyrimidin-1(2H)yl)-4,4-difluoro-3 hydroxytetrahydrofuran-2-yl)methyl (2-(5-(2-oxohexahydro-1H-thieno[3,4d]imidazol-4-yl)pentanamido)ethyl) carbonate): The protocol for the preparation of $\mathbf{4}$ is shown in Figure 1. The synthesis of $\mathbf{2}$ has previously been described [13]. To a dichloromethane (DCM) (10 mL) solution of $2(0.28 \mathrm{~g}, 0.9 \mathrm{mmol})$, 4-nitrophenyl chloroformate $(0.59 \mathrm{~g}, 2.9 \mathrm{mmol})$, diisopropylethylamine (DIPEA) $(0.50 \mathrm{~g}, 3.9 \mathrm{mmol})$ and a catalytic amount of pyridine were added at $0^{\circ} \mathrm{C}$ and then stirred for $24 \mathrm{hrs}$ at $18^{\circ} \mathrm{C}$. The reaction mixture was then concentrated to dryness and the crude residue containing 3 dissolved in $20 \mathrm{~mL}$ of DMF. To this solution, Gem (0.88g, $2.9 \mathrm{mmol})$ in DMF $(5 \mathrm{~mL})$ and TEA $(1 \mathrm{~mL})$ were added and the mixture stirred for a further $24 \mathrm{hrs}$ at $18^{\circ} \mathrm{C}$. After completion of the reaction (monitored by Thin layer chromatography (TLC)), excess diethyl ether $(200 \mathrm{~mL})$ was added to the reaction mixture and stirred for a further $45 \mathrm{~min}$ at $18^{\circ} \mathrm{C}$. The pale yellow oil obtained was separated and washed 
three times with cold diethyl ether $(50 \mathrm{~mL} \times 3)$. The crude compound was purified by preparative TLC using DCM / MeOH $(9: 1)$ as eluent to afford the target compound $4(0.12 \mathrm{~g}$, $22 \%$ yield). ${ }^{1} \mathrm{H}$ NMR, 500MHz (DMSO- $\left.\mathrm{d}_{6}\right): \delta$ 7.99-7.91 (m, 3H, CH, NH $\left.\mathrm{H}_{2}\right), 6.41-6.33(\mathrm{~m}, 1 \mathrm{H}$, $\mathrm{CH})$, 6.12-6.01 (m, 3H, CH, NH X 2), 4.30-4.16 (m, 1H, CH), 4.19-4.12 (m, 3H, CH, $\left.\mathrm{CH}_{2}\right)$, 3.90-3.75 (m, $\left.2 \mathrm{H}, \mathrm{CH}_{2}\right), 3.69-3.58\left(\mathrm{~m}, 2 \mathrm{H}, \mathrm{CH}_{2}\right), 3.12-3.09(\mathrm{~m}, 1 \mathrm{H}, \mathrm{CH}), 2.93-2.88(\mathrm{~m}, 2 \mathrm{H}$, $\mathrm{CH}_{2}$ ), 2.83 (brs, $\left.1 \mathrm{H}, \mathrm{OH}\right), 2.82-2.77$ (m, 2H, CH X2), 2.72 (brs, $\left.1 \mathrm{H}, \mathrm{NH}\right), 2.49-2.04(\mathrm{~m}, 2 \mathrm{H}$, $\left.\mathrm{CH}_{2}\right), 1.49-1.28\left(\mathrm{~m}, 6 \mathrm{H}, \mathrm{CH}_{2} \times 3\right) .{ }^{13} \mathrm{C}$ NMR, $125 \mathrm{MHz}$ (DMSO-d $): 175.0(\mathrm{C}=\mathrm{O}), 166.3(\mathrm{C})$, $165.5(\mathrm{C}=\mathrm{O}), 156.3(\mathrm{C}=\mathrm{O}), 156.1(\mathrm{C}=\mathrm{O}), 141.3(\mathrm{CH}), 125.3(\mathrm{C}), 95.2(\mathrm{CH}), 79.2(\mathrm{CH}), 67.2$ $(\mathrm{CH}), 61.9(\mathrm{CH}), 60.2\left(\mathrm{OCH}_{2}\right), 55.5\left(\mathrm{OCH}_{2}\right), 39.6(\mathrm{CH}), 37.8\left(\mathrm{CH}_{2}\right), 35.2(\mathrm{CH}), 28.3\left(\mathrm{CH}_{2}\right), 28.0$ $\left(\mathrm{CH}_{2}\right), 25.3\left(\mathrm{CH}_{2}\right)$. ESI-MS: calculated for $\mathrm{C}_{22} \mathrm{H}_{30} \mathrm{~F}_{2} \mathrm{~N}_{6} \mathrm{O}_{8} \mathrm{~S}$, 576.18; found $577.2(\mathrm{M}+\mathrm{H})$.

2.3 Preparation of $\mathrm{O}_{2} M B-G e m$ and $\mathrm{O}_{2} M B-R B$ : We have described the preparation of the $\mathrm{O}_{2} \mathrm{MB}-\mathrm{RB}$ conjugate in a previous communication [12]. A similar procedure was used for the preparation of the $\mathrm{O}_{2} \mathrm{MB}-\mathrm{Gem}$ conjugate with the exception of exchanging the biotin-RB (structure 5, Fig 1) for biotin-Gem (4). The MB number and size were determined by withdrawing $10 \mu \mathrm{L}$ samples of the $\mathrm{O}_{2} \mathrm{MB}-\mathrm{RB}$ and $\mathrm{O}_{2} \mathrm{MB}-\mathrm{Gem}$ conjugates and diluting them separately in $90 \mu \mathrm{L}$ of PBS $(\mathrm{pH} 7.4 \pm 0.1)$ followed by analysis using a haemocytometer (Bright-Line, Hausser Scientific, Horsham, PA, USA). Images were obtained with a x40 objective lens using a Leica DM500 optical microscope. The MB size distribution was then determined through image analysis using ImageJ software. The brightfield image was converted to 8-bit greyscale before an automated threshold strategy was applied to eliminate out of focus MBs. Particle diameter was then calculated relative to the scale bar present in the brightfield image. Where appropriate, the $\mathrm{O}_{2} \mathrm{MB}-\mathrm{RB}$ and $\mathrm{O}_{2} \mathrm{MB}-\mathrm{Gem}$ conjugates were mixed together in a 1:1 ratio for combined chemo-sonodynamic therapy treatments. Fluorescence imaging of the mixed MB suspension was performed using a Nikon Eclipse E400 epifluorescence microscope equipped and the G-2A longpass emission filter set $\left(\lambda_{E x} 510-560\right.$, $80 \%$ transmission with a $590 \mathrm{~nm}$ cut-on wavelength of the longpass emission) to confirm successful drug loading. The drug loading on the surface of the MB conjugates was further 
assessed using UV-Vis spectroscopy for $\mathbf{5}$ and reverse phase HPLC for $\mathbf{4}$, using a Phenomenex C18 column ( $250 \times 4.6 \mathrm{~mm}, 5 \mu \mathrm{m})$, a mobile phase consisting of acetonitrile:1.5 $\mathrm{mM}$ potassium phosphate monobasic (5:95 v/v), a flow rate of $1.0 \mathrm{~mL} / \mathrm{min}^{-1}$ using $206 \mathrm{~nm}$ as the detection wavelength.

2.4 Cytotoxicity of chemo-sonodynamic therapy in vitro: The human primary pancreatic carcinoma cell lines MIA PaCa-2 and PANC-1 were maintained in Dulbecco's Modified Eagle's Medium (DMEM) containing high glucose $(4.5 \mathrm{~g} / \mathrm{L})$ and while adenocarcinoma BxPC3 cells were maintained in RPMI-1640 medium, all of which were supplemented with $10 \%(\mathrm{v} / \mathrm{v})$ foetal bovine serum in a humidified $5 \% \mathrm{CO}_{2}$ atmosphere at $37^{\circ} \mathrm{C}$. A mouse pancreatic cancer cell line (T110299) was derived from a primary pancreatic tumour of a genetically modified KPC mouse model. [14] T110299 cells were maintained in high glucose DMEM with 10\% FBS, 1\% Non-Essential Amino Acids, 1\% L-glutamine and 1\% Pen/Strep. $5 \times 10^{3}$ cells were seeded in 96 well plates and placed in an incubator $\left(37^{\circ} \mathrm{C}, 5 \% \mathrm{CO}_{2}\right)$ and $24 \mathrm{hrs}$ later were treated with a $50 \mu \mathrm{L}$ suspension of either $\mathrm{O}_{2} \mathrm{MB}-\mathrm{Gem}, \mathrm{O}_{2} \mathrm{MB}-\mathrm{RB}$ or a combination of $\mathrm{O}_{2} \mathrm{MB}-\mathrm{Gem} / \mathrm{O}_{2} \mathrm{MB}-\mathrm{RB}$ $[\mathrm{MB}]=2.7 \times 10^{6} ;[\mathrm{RB}]=[\mathrm{Gem}]=5 \mu \mathrm{M}$. After 3 hours, selected wells were treated with ultrasound delivered using a Sonidel SP100 sonoporator $\left(1 \mathrm{MHz}, 30\right.$ seconds, $3 \mathrm{Wcm}^{-2}$, duty cycle $=50 \%$, and PRF $=100 \mathrm{~Hz}$ ). The peak negative pressure $(\mathrm{PNP})$ was $0.25 \mathrm{MPa}$, providing a mechanical index (MI) of 0.25 at this frequency. Untreated cells and cells treated with ultrasound only were used for comparative purposes. After 24 hours, cellular metabolic activity was determined using a MTT assay. For the efficacy comparison between Gem and BiotinGem (4), $5 \times 10^{3}$ BxPC3 and MIA PaCa-2 cells were seeded in 96 well plates, placed in an incubator $\left(37^{\circ} \mathrm{C}, 5 \% \mathrm{CO}_{2}\right)$ and $24 \mathrm{hrs}$ later were treated with $0,5,10,25$ and $100 \mu \mathrm{M}$ of Gem or 4 and cell viability determined using a MTT assay 48 hrs later.

2.5 Cytotoxicity of chemo-sonodynamic therapy in vivo: All animals employed in this study were treated in accordance with the licenced procedures under the UK Animals (Scientific Procedures) Act 1986. MIA PaCa-2 cells $\left(5 \times 10^{6}\right)$ in $100 \mu \mathrm{L}$ Matrigel were sub-cutaneously implanted into the rear dorsum of SCID (C.B-17/IcrHan®Hsd-Prkdcscid) mice. Tumours 
started to form approximately 1-2 weeks after cell implantation. Once the tumour became palpable, dimensions were measured using Vernier callipers. The geometric mean diameter was used to determine tumour volume using the equation tumour volume $=4 \pi R^{3} / 3$. When tumours reached an average of $207 \mathrm{~mm}^{3}$, the animals were randomly distributed into six groups (Table 1$)(n=5)$. Group 1 received an intravenous (IV) tail vein injection $(100 \mu \mathrm{L})$ of a mixed $\mathrm{O}_{2} \mathrm{MB}-\mathrm{Gem} / \mathrm{O}_{2} \mathrm{MB}-\mathrm{RB}$ suspension containing $2.4 \times 10^{8} \mathrm{MB} \mathrm{mL}^{-1}, 443 \mu \mathrm{M}$ Gem $(0.464$ $\mathrm{mg} / \mathrm{kg})$ and $557 \mu \mathrm{M}, \mathrm{RB}(2.164 \mathrm{mg} / \mathrm{kg})$ as well as receiving ultrasound applied to the tumour and delivered using a Sonidel SP100 sonoporator $\left(3.5 \mathrm{Wcm}^{-2}, 1 \mathrm{MHz}, 30 \%\right.$ duty cycle, and $\mathrm{PRF}=100 \mathrm{~Hz} ; \mathrm{PNP}=0.48 \mathrm{MPa} ; \mathrm{MI}=0.48$ ) during and after injection (for a total of $3.5 \mathrm{~min}$ ) with a second 3.5 min ultrasound exposure 30 min following injection; group 2 received the same MB treatment as Group 1 but were not exposed to ultrasound; Group 3 received ultrasound treatment alone using the same parameters as for Group 1; Group 4 received the same treatment as Group 1 but also received an additional treatment $72 \mathrm{hrs}$ following the initial treatment; Group 5 received no treatment and Group 6 received an intraperitoneal (IP) injection of Gem (dissolved in 5\% DMSO : 95 \%PBS) at a concentration of $120 \mathrm{mg} / \mathrm{kg}$ (106.3 $\mathrm{mM}$ ) on Day 0 (0 hrs) and Day 3 (72 hrs). Tumour volume and mouse weight were measured daily for 8 days following the initial treatment.

\section{Table 1: Treatment groups of SCID mice bearing ectopic Mia Paca-2 tumours}

\begin{tabular}{l|l} 
Group & Treatment condition \\
\hline $\mathbf{1}$ & IV injection of the $\mathrm{O}_{2} \mathrm{MB}-\mathrm{Gem} / \mathrm{O}_{2} \mathrm{MB}-\mathrm{RB}$ conjugate + US treatment on day 0 \\
\hline $\mathbf{2}$ & IV injection of the $\mathrm{O}_{2} \mathrm{MB}-\mathrm{Gem} / \mathrm{O}_{2} \mathrm{MB}-\mathrm{RB}$ conjugate alone \\
\hline $\mathbf{3}$ & US treatment alone \\
\hline $\mathbf{4}$ & IV injection of the $\mathrm{O}_{2} \mathrm{MB}-\mathrm{Gem} / \mathrm{O}_{2} \mathrm{MB}-\mathrm{RB}$ conjugate + US treatment on day 0 and day 3 \\
\hline $\mathbf{5}$ & Untreated \\
\hline $\mathbf{6}$ & IP injection of the Gem alone
\end{tabular}


2.6 Determining the effect of chemo-sonodynamic therapy at the genetic level: To establish the effect of combined chemo-sonodynamic therapy on the expression of specific genes involved in the development and progression of pancreatic cancer, tumours in mice from Groups 1 and 5 were removed post-mortem following the final measurement on Day 8. Tumours were snap-froze using liquid nitrogen and RNA was extracted using Trizol reagent (Life Technologies) in accordance with the manufacturer's instructions [15]. $1 \mu \mathrm{g}$ of RNA per tumour was reverse transcribed using First Strand cDNA synthesis kit (Roche) in accordance with manufacturer's instructions [16] and the cDNA from the tumours in each group were pooled. Samples were analysed in duplicate on Roche RealTime Ready custom 96 well panels (Roche) analysing nine specific genes involved in pancreatic cancer. The genes investigated were vascular endothelial growth factor (VEGFC), interleukin 8 (IL8), SMAD family member 4 (SMAD4), hypoxia inducible factor 1 (HIF1A), von Hippel-Lindau (VHL), runt-related transcription factor (RUNX2), sex determining region Y-box 2 (SOX2), NANOG, epithelial cell adhesion molecule (EPCAM). The results were normalised to a reference gene set (Beta actin, 18s ribosomal RNA and GAPDH) and the percentage change in gene expression for treated compared to untreated tumours was determined.

\subsection{Determining the toxicity of $\mathrm{O}_{2} \mathrm{MB}-\mathrm{Gem} / \mathrm{O}_{2} \mathrm{MB}-\mathrm{RB}$ treatment in healthy non-tumour}

bearing mice: Healthy MF1 mice ( 8 week old) were randomly distributed into 4 groups $(n=10$; 5 female and 5 male). Group 1 received no treatment; Group 2 received a $100 \mu \mathrm{L}$ IV injection the mixed $\mathrm{O}_{2} \mathrm{MB}-\mathrm{Gem} / \mathrm{O}_{2} \mathrm{MB}-\mathrm{RB}$ suspension containing $\left(2.6 \times 10^{8} \mathrm{MB} \mathrm{mL}^{-1}, 480.0 \mu \mathrm{M}\right.$ Gem and $610.0 \mu \mathrm{M} \mathrm{RB})$ while Groups $3 \& 4$ received $100 \mu \mathrm{L}$ IV of Gem $(57.0 \mathrm{mM})$ or RB (1.0 mM) respectively. A second treatment was also administered 3 days after the initial treatment. Blood samples were taken 15 days following treatment and transferred to CTDS Ltd (Garforth, UK) for whole blood and plasma biochemistry analysis. After harvesting blood samples, animals were sacrificed and the liver / kidneys placed in formalin free fixative for 24 hours. 
The tissues were then placed in an automated tissue processor, Leica TP1020 system, passed between increasing concentrations of ethanol followed by xylene treatment and paraffin wax embedding. The following day, the wax embedded tissue samples were placed in moulds containing paraffin wax. Once the wax blocks had solidified, $5 \mu \mathrm{m}$ sections were cut, placed on a glass slide and stained with haematoxylin and eosin (H\&E) using an automated staining protocol. In some cases, additional stains (i.e. reticulin, Masson's trichrome, Perl's Prussian blue stain) were used when necessary. The stained sections were reviewed histologically by pathologists with expertise in liver and renal pathology. Liver architecture was initially assessed to establish if there was significant remodelling or fibrosis. The various liver compartments were subsequently examined for pathological changes. Portal tract and lobular inflammation grading was adapted from the Ishak (modified HAI) system [17]. Portal tract inflammation was graded numerically from 1 (none) to severe, affecting all portal tracts. Lobular inflammation was assessed at $\times 10$ magnification and graded as 1 (none) to 4 (severe, typically averaging $>10$ foci per $\times 10$ field). Fatty liver disease grading, referred to as steatosis/steatohepatitis, was undertaken based on parameters assessed in the NAFLD activity score [18]. In short, steatosis was graded based on a visual estimate of the percentage of liver cells affected as $1=$ none or less than $5 \% ; 2=$ mild, $(5-33 \%) ; 3=$ moderate $(34-66 \%)$ and $4=$ severe (greater than 67\%). Kidney analysis was undertaken following a similar approach assessing the glomerular cellularity, glomerular basement membrane, tubular vacuolation, interstitial inflammation, interstitial fibrosis, vessel integrity and the collecting system.

2.8 Statistical Analysis: Error was reported as \pm standard error of the mean. Statistical analysis was undertaken using a SPPS statistical package (IBM, UK). Group-wise comparisons were made using one-sided parallel group t-tests with a $p$-value less than 0.05 deemed significant. 
3.0 Results and Discussion: Biotin-Gem (4) was synthesised in four steps following the procedures outlined in Figure 1. Succinimide activated biotin (1) was first reacted with 2aminioethanol via an amidation reaction to generate the alcohol functionalised biotin derivative 2. 2 was then reacted with 4-nitrophenyl chloroformate to generate intermediate $\mathbf{3}$, which when reacted with Gem resulted in the formation of the target compound 4, with the biotin unit attached to the primary alcohol of Gem via a carbonate ester. The preparation of biotin-RB (5) has been reported by us in a previous communication [12].

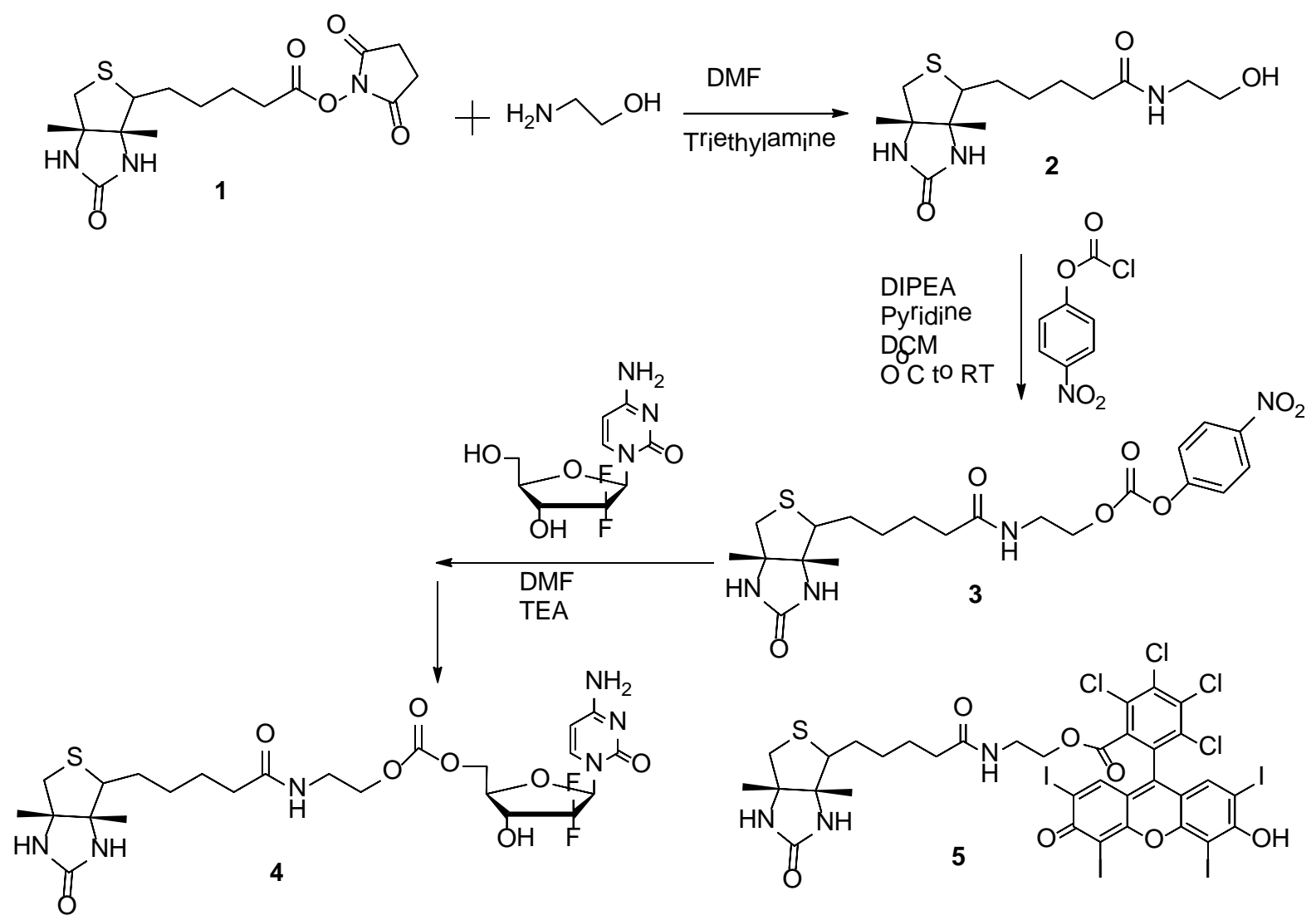

Figure 1 Synthetic scheme for the preparation of Biotin-Gem (4) with the structure of biotinRose Bengal (5) also shown.

Avidin functionalised lipid-stabilised MB were also prepared following a method reported by us previously [12]. Briefly, the phospholipids DBPC, DSPE-PEG(2000) and DSPEPEG(2000)-biotin, in a ratio of 82:9:9 were sonicated at above their phase transition 
temperature in the presence of perfluorobutane (PFB) gas. The presence of DSPEPEG(2000)-biotin in the lipid shell enabled the subsequent functionalisation of the MB surface with avidin using the facile biotin-avidin interaction. As avidin has four binding sites for biotin, the three remaining sites can be used to load biotinylated payloads such as $\mathbf{4}$ or $\mathbf{5}$, producing PFB-MB-Gem or PFB-MB-RB conjugates respectively, which after sparging with oxygen gas generated the $\mathrm{O}_{2} \mathrm{MB}-\mathrm{Gem}$ or $\mathrm{O}_{2} \mathrm{MB}-\mathrm{RB}$ conjugate (Fig 2).
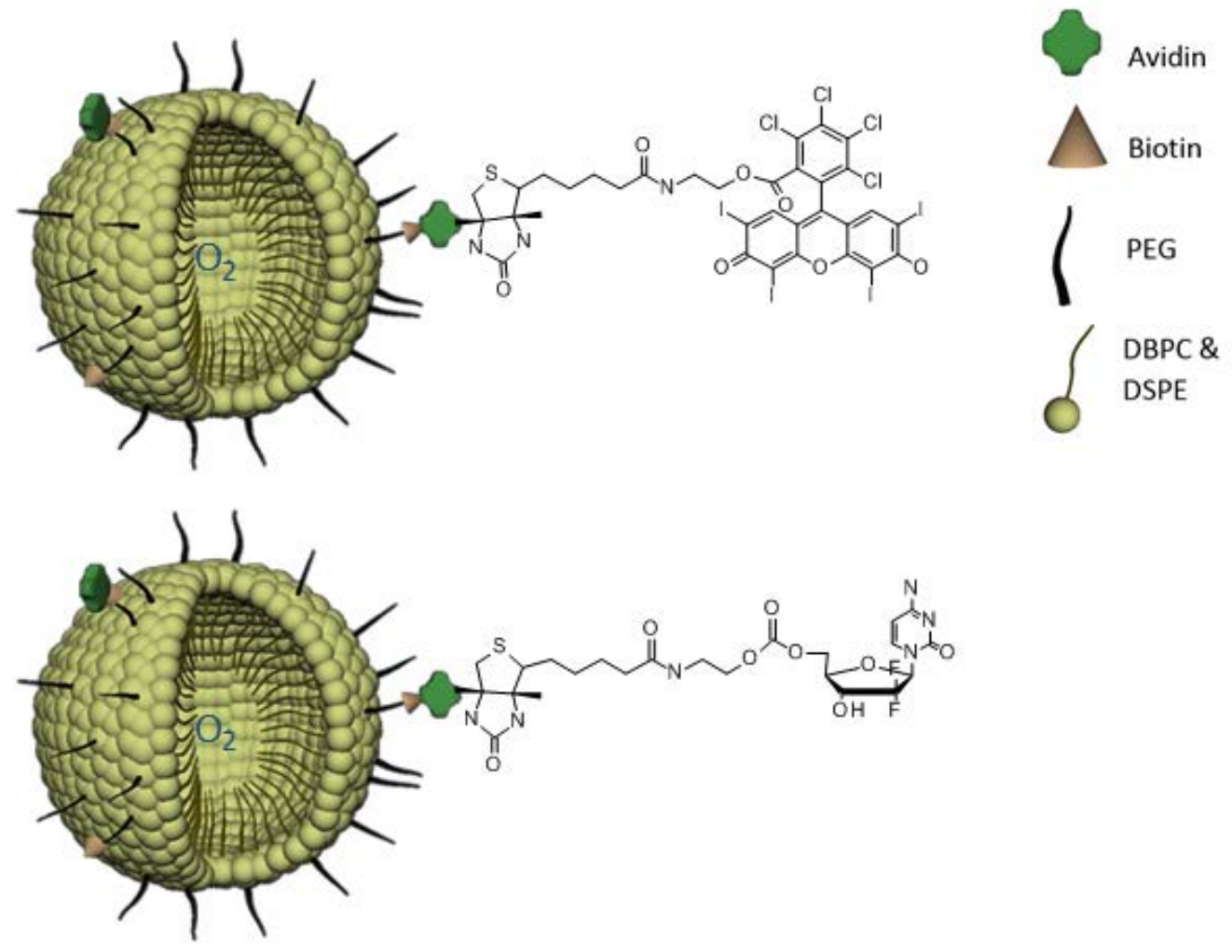

Figure 2 Schematic representation of the structure of the (a) $\mathrm{O}_{2} \mathrm{MB}-\mathrm{RB}$ (top) and (b) $\mathrm{O}_{2} \mathrm{MB}$ Gem (bottom) conjugates.

For joint chemo-sonodynamic therapy treatments, the $\mathrm{O}_{2}-\mathrm{MB}-\mathrm{Gem}$ or $\mathrm{O}_{2}-\mathrm{MB}-\mathrm{RB}$ conjugates were mixed together in a 1:1 ratio. A representative fluorescence image of the mixed $\mathrm{O}_{2} \mathrm{MB}-\mathrm{Gem} / \mathrm{O}_{2} \mathrm{MB}-\mathrm{RB}$ suspension is shown in Fig 3 and reveals spherical particles with an average diameter of $1.5 \pm 0.9 \mu \mathrm{m}$ and the characteristic red fluorescence of Rose Bengal when excited at $548 \mathrm{~nm}$ indicating its successful loading onto the MB shell. As Gem is non-fluorescent, it wasn't possible to confirm its loading by fluorescence microscopy. 
However, the amount of Gem attached to the MB surface was determined by HPLC following destruction of a fixed volume of the MB suspension.

(a)

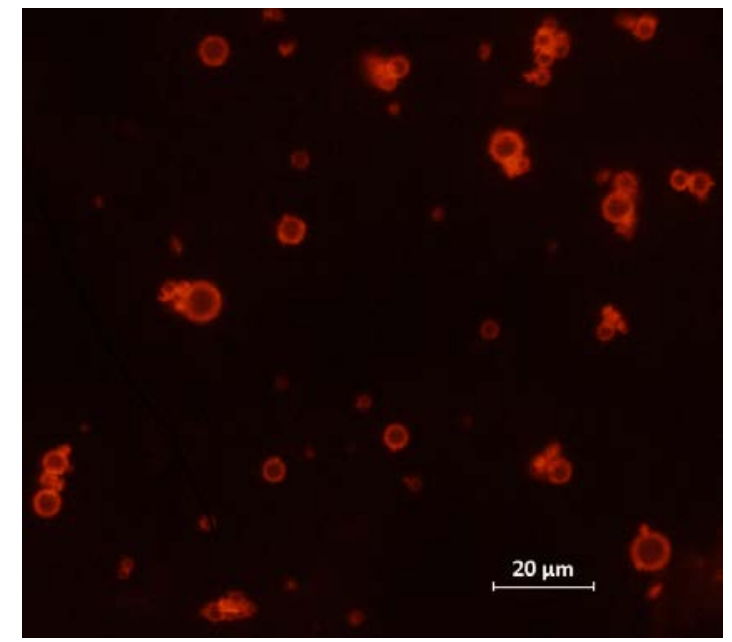

(b)

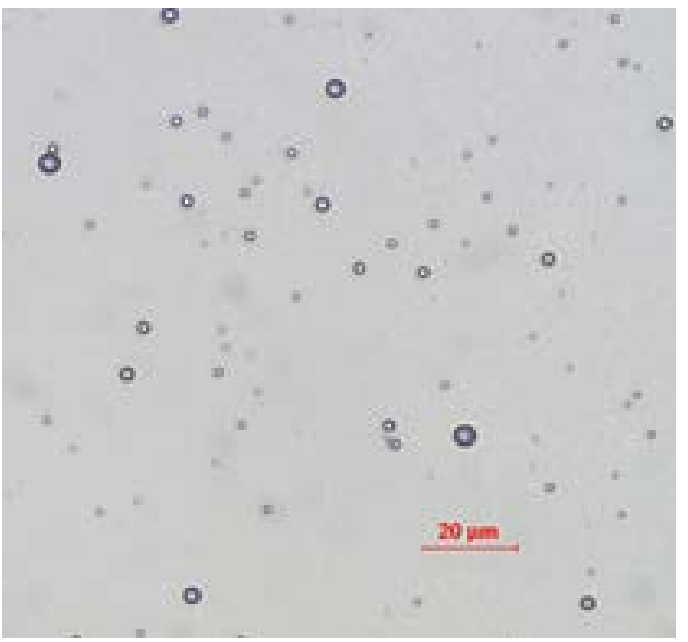

(c)

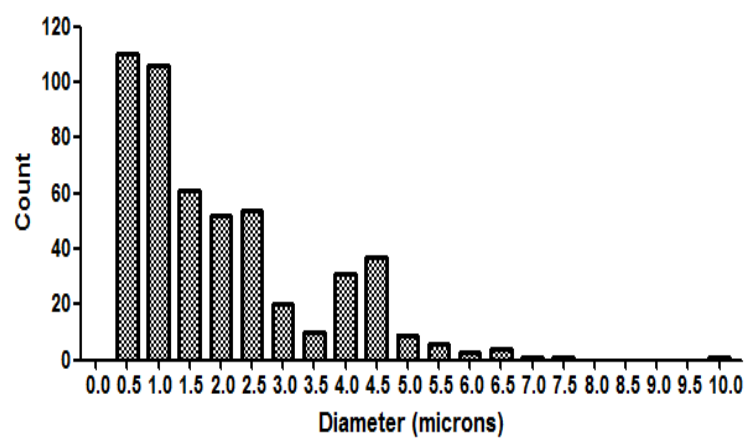

Figure 3 (a) Representative fluorescence and (b) brightfield images obtained for a sample of the mixed $\mathrm{O}_{2} \mathrm{MB}-\mathrm{RB} / \mathrm{O}_{2} \mathrm{MB}-\mathrm{Gem}$ suspension $\left(\lambda_{\mathrm{EX}}=548 \mathrm{~nm}\right.$ and $\lambda_{\mathrm{EM}}=565 \mathrm{~nm}$ ). (c) Size distribution obtained the mixed $\mathrm{O}_{2} \mathrm{MB}-\mathrm{Gem} / \mathrm{O}_{2} \mathrm{MB}-\mathrm{RB}$ suspension in brightfield mode.

When drug compounds such as Gem have been structurally modified, it is imperative to ensure that the resulting derivative is as active as the parent drug so that the therapeutic effect can be maintained. Gem itself is a prodrug and requires phosphorylation to the di- or triphosphate by kinase enzymes before it can disrupt DNA synthesis [19]. This phosphorylation event occurs at the primary alcohol functional group of Gem, which was converted to the 
carbonate ester in 4 to enable attachment of biotin. Therefore, to ensure this structural modification did not hamper the efficacy of $\mathbf{4}$, a dose response experiment was conducted where MIA PaCa-2 and BxPC-3 cells were incubated with either Gem or 4 at a range of concentrations and the cell viability determined 48 hrs later using a MTT assay.

(a)

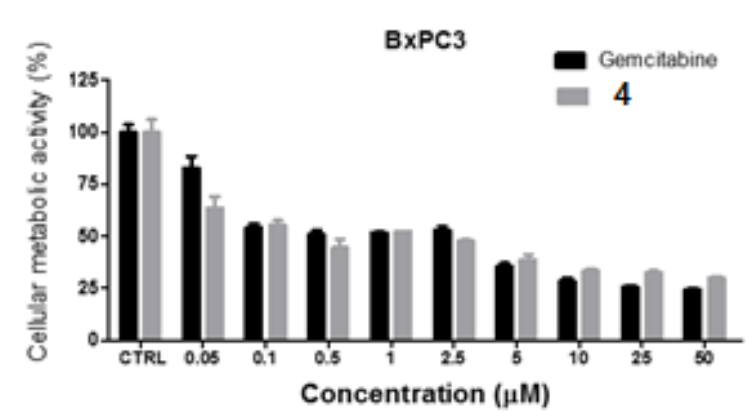

(b)

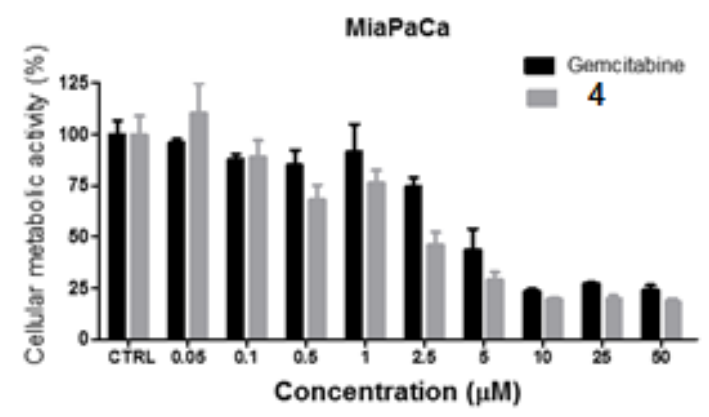

Figure 4 Plot of cellular metabolic activity determined $48 \mathrm{hrs}$ following treatment of (a) BxPC3 and (b) MIA PaCa-2 cells with various concentrations of Gem or 4 (biotin-Gem).

The results reveal that 4 and Gem have similar cytotoxicity in the BxPC3 cell line with $L_{50}$ values of 1.26 and $0.84 \mu \mathrm{M}$ respectively, while in the MiaPaCa-2 cells 4 was slightly more toxic than Gem with $L_{50}$ values of 1.38 and $3.58 \mu \mathrm{M}$ respectively. The reason for the slightly enhanced cytotoxicity for $\mathbf{4}$ over Gem is not fully understood but these results suggest that 4 is rapidly converted to Gem once taken up by MIA PaCa-2 and BXPC3 cells resulting in toxicity similar, if not slightly greater than, Gem itself. While the mechanism for this transformation is not certain, it has previously been demonstrated that carbonate esters such as that present in 4 are susceptible to cleavage by endogenous thiols and this is the most likely reason for the intracellular liberation of Gem from 4. [20]

Having ensured the activity of $\mathbf{4}$ relative to Gem itself, the next step was to determine the effectiveness of chemo-sonodynamic therapy using the mixed $\mathrm{O}_{2} \mathrm{MB}-\mathrm{Gem} / \mathrm{O}_{2} \mathrm{MB}-\mathrm{RB}$ suspension in a panel of pancreatic cancer cells. Human pancreatic cancer cell lines MIA PaCa-2, PANC-1 and BxPC3, as well as the mouse pancreatic cancer cell line T110299, were 
used as targets. In the experiment comparing Gem and 4 above, a significant toxicity was observed for 4 at $5 \mu \mathrm{M}$ in both cell lines when incubated for $48 \mathrm{~h}$. However, in order to demonstrate the potential benefit of combining Gem therapy with SDT using the MB formulation, it is important to identify conditions that result in a sub-lethal effect from Gem and SDT treatment alone, so that any positive benefit by combining the two treatments can be determined. To ensure this, the $\mathrm{O}_{2} \mathrm{MB}-\mathrm{Gem}$ and $\mathrm{O}_{2} \mathrm{MB}-\mathrm{RB}$ concentration used was $5 \mu \mathrm{M}$ (i.e. the Gem and RB concentration) but the incubation period was reduced to $3 \mathrm{~h}$ and the MTT assay recorded $24 \mathrm{~h}$ after treatment. Cells were treated as described in Section 2.4 and the results, shown in Following the incubation period, cells were then either treated or not with ultrasound, using a power density of $3 \mathrm{~W} \mathrm{~cm}^{-2}$, a frequency of $1 \mathrm{MHz}$, a $50 \%$ duty cycle, and a pulse repetition frequency of $100 \mathrm{~Hz}$ for a total of 30 seconds. Experiments were also conducted using the $\mathrm{O}_{2} \mathrm{MB}-$-Gem conjugate or $\mathrm{O}_{2} \mathrm{MB}-\mathrm{RB}$ conjugate plus ultrasound, to identify the effect of MB mediated Gem or SDT treatment alone. Untreated cells and cells treated with ultrasound alone were also used for comparative purposes. in Fig 5 and reveal a significant reduction in cellular metabolic activity for cells treated with combined chemo-sonodynamic therapy relative to those treated with Gem or SDT monotherapy in three (BxPC3, MiaPaCa-2 and Panc-01) of the four cell lines tested. While a small reduction was also observed for the T110299 cell line, this was not significant when compared to O2MB-Gem + US treatment alone. While the reason for this is not fully understood, it may be that this mouse derived cell line is more sensitive to ultrasound induced sonoporation effects than the human derived cell lines, leading to enhanced uptake of gemcitabine. Nonetheless, as reported in our previous work that investigated combing 5-FU chemotherapy and SDT, antimetabolite chemotherapy using Gem also complements SDT, significantly enhancing the observed cytotoxic effect. 


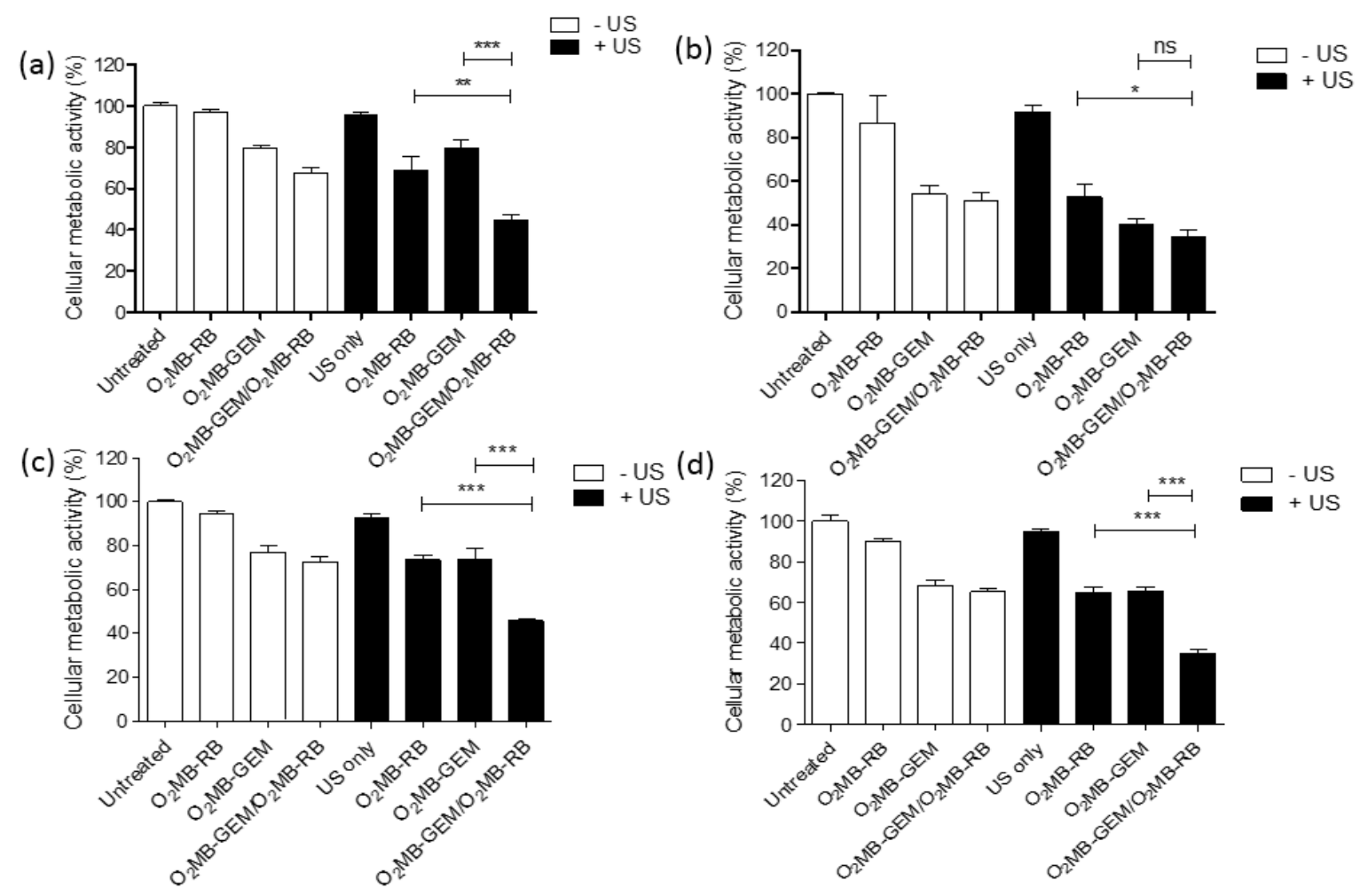

Figure 5 Plot of \% cellular metabolic activity for (a) BxPC3 (b) T110299 (c) MIA PaCa-2 and (d) Panc-01 cells following treatment with (i) untreated, (ii) ultrasound only, (iii) $\mathrm{O}_{2} \mathrm{MB}-\mathrm{RB}$ only, (iv) $\mathrm{O}_{2} \mathrm{MB}-\mathrm{RB}$ plus ultrasound, (v) $\mathrm{O}_{2} \mathrm{MB}-\mathrm{Gem}$ only, (vii) combined $\mathrm{O}_{2} \mathrm{MB}-\mathrm{Gem}$ and $\mathrm{O}_{2} \mathrm{MB}-\mathrm{RB}$, (viii) combined $\mathrm{O}_{2} \mathrm{MB}-\mathrm{RB}$ and $\mathrm{O}_{2} \mathrm{MB}-\mathrm{Gem}$ plus ultrasound. ${ }^{*} \mathrm{p}<0.05$, ${ }^{* \star} \mathrm{p}<0.01$, $\star * \star p<0.001$. Error bars represent \pm the standard error, $n=6$.

While the above in vitro studies were promising and revealed the benefit of combining Gem and SDT for the treatment of pancreatic cancer, in vivo experiments are necessary to fully explore the aspect of drug targeting and efficacy using UTMD. To this end, sub-cutaneous human xenograft MIA PaCa-2 tumours were established in SCID mice. MIA-PaCa tumours are poorly vascularised resulting in extremely hypoxic tumours (pO2 $\sim 2.0 \mathrm{mmHg}$ ). Indeed, this tumour model has previously been used in therapeutic efficacy experiments involving hypoxia activated prodrugs [21]. The mice were treated as described in 2.5 Once the tumours had reached an average volume of $207 \pm 20 \mathrm{~mm}^{3}$, the mice were randomly allocated into 6 groups. Group 1 received an IV injection of the mixed $O_{2} M B-G e m / O_{2} M B-R B$ suspension with tumours exposed to ultrasound for $3.5 \mathrm{~min}$ during and after injection ( $3.5 \mathrm{~min}$ total). A second ultrasound treatment was also applied 30 min after injection to activate the Rose Bengal. 
Group 2 also received an IV injection of the mixed $\theta_{2}$ AB-Gem $/ \theta_{2}$ MB-RB suspension but did not receive ultrasound treatment, while group 3 received ultrasound treatment alone. Group 4 received the same treatment as group 1 but also received a second identical treatment $72 \mathrm{~h}$ following the first treatment, while untreated animals (group 5) were used as a control. The final group (group 6) received an IP injection of Gem monotherapy at a scaled clinically relevant dose (120 mg/kg) [20]. Tumour volumes were recorded each day for 8 days following the initial treatment and the results are shown in Fig 6. 
(a)

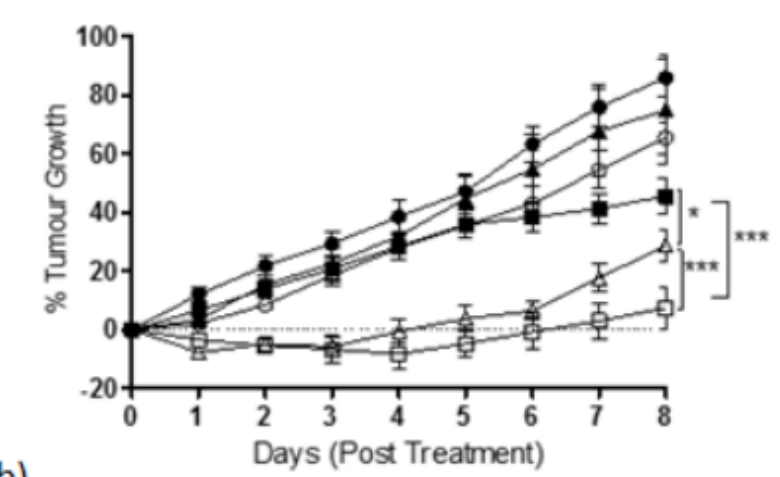

(b)

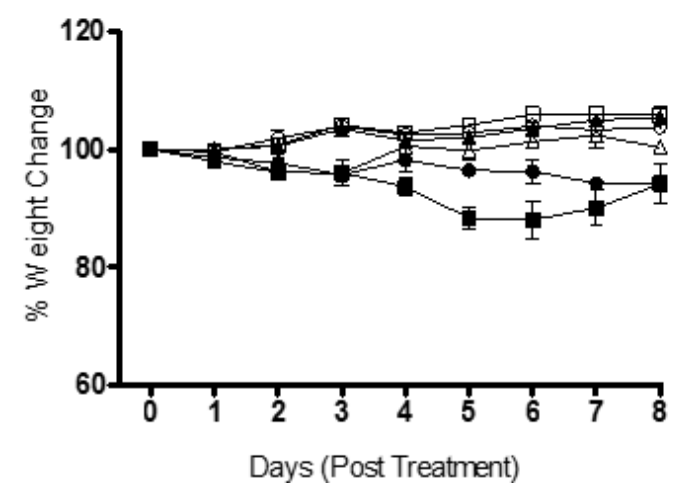

Figure 6 (a) Plot of tumour growth and (b) mouse weight versus time for mice bearing human xenograft MIA PaCa-2 tumours treated with (i) $\mathrm{O}_{2} \mathrm{MB}-\mathrm{Gem} / \mathrm{O}_{2} \mathrm{MB}-\mathrm{RB}$ on Day $0+$ ultrasound (open triangle $-\Delta$ ), (ii) $\mathrm{O}_{2} \mathrm{MB}-\mathrm{Gem} / \mathrm{O}_{2} \mathrm{MB}-\mathrm{RB}$ on Day 0 and Day $3+$ ultrasound (open square $\square^{-}$), (iii) $\mathrm{O}_{2} \mathrm{MBGem} / \mathrm{O}_{2} \mathrm{MB}-\mathrm{RB}$ on Day 0 and Day 3 - ultrasound (filled triangle - ), (iv) ultrasound only (open circle - ), (v) Gem IP at $120 \mathrm{mg} / \mathrm{kg}$ (filled square - ) , and (vi) no treatment (filled circle ${ }^{-}$). $. n=5$.

No significant difference in tumour growth delay was observed for animals in groups 2 and 3 compared to untreated animals indicating that ultrasound or MB conjugate treatment alone had no significant effect on tumour growth. In contrast, for animals in groups 1 and 5, a significant reduction in tumour growth was observed suggesting the UTMD approach facilitated tumour delivery of Gem and Rose Bengal enabling effective chemo-sonodynamic therapy treatment. Indeed, tumours in both these groups reduced in volume from their pre- 
treatment size by $6.5 \%$ three days following treatment. While the tumours of animals in group 1 returned to their pre-treatment size on day 4, for animals in group 5 that received a second chemo-sonodynamic therapy treatment on day 3 , the tumour volume remained below pretreatment size until day 7 . To place these results in context, tumour growth in animals treated with systemic Gem monotherapy (group 6) at no time reduced below their pre-treatment value. Indeed, 8 days following treatment, the tumours were $45.5 \%$ greater than their pre-treatment volume compared to $7.3 \%$ for those in group 5, despite the former receiving a Gem dose 240 times higher. The ability to downstage tumours in pancreatic cancer is particularly relevant as a significant proportion of patients present with LAPC or BRPC and treatments that can reduce tumour volume are valuable neo-adjuvant tools to help improve resection rates and ultimately, survival rates. Additionally, as shown for group 5, the ability to maintain tumour growth delay with a second exposure to chemo-sonodynamic therapy (i.e. group 4) means this treatment could also have potential use in the management of metastatic pancreatic cancer, where balancing extension of life with quality of life is an important consideration. Analysis of animal body weights during treatment (Fig $6 b)$ revealed a significant $(p \leq 0.001)$ a $12 \%$ reduction in weight for animals treated with Gem monotherapy 5 days following treatment, while the weight of animals treated with $\mathrm{MB}$ delivered Gem/RB grew over the same time period. While it is acknowledged that the mode of administration for Gem only and MB delivered Gem/RB was different, the increased toxicity for Gem only was most likely due to acute systemic toxicity due to the significantly higher dose and lack of targeting. Therefore, not only was UTMD mediated chemo-sonodynamic therapy more effective than Gem monotherapy, it was also much better tolerated. A key benefit of this particular dual therapy is that RB at the doses employed here is non-toxic and only generates cytotoxic ROS on exposure to ultrasound. This means that the improved cytotoxicity observed through combination of the two treatments does not come at the cost of increased systemic related toxicity that would normally be expected when two conventional chemotherapy treatments are combined together. Furthermore, as Gem delivery can be controlled through UTMD, a significantly lower overall 
concentration of the drug can be administered to patients, thereby reducing the likelihood of systemic side effects.

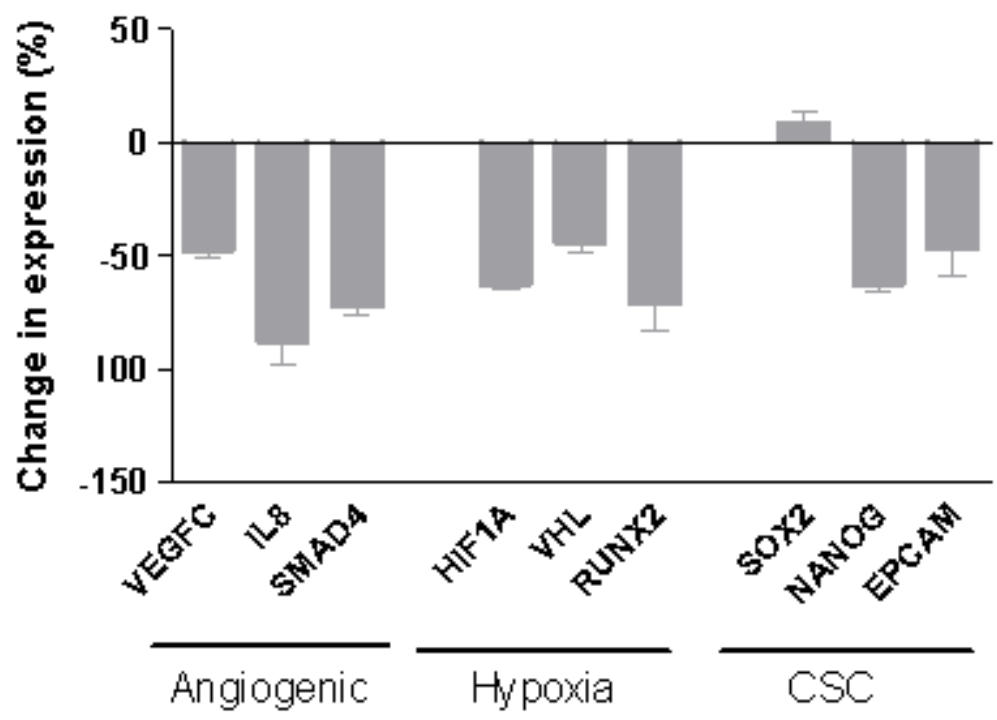

Figure 7 Plot showing \% change in expression of nine genes associated with pancreatic cancer for treated tumours relative to untreated tumours.

We also explored the effect of chemo-sonodynamic therapy on key genes involved in the development and progression of pancreatic cancer. To do this, tumours in groups 1 and 5 were harvested and the expression of selected genes determined using qPCR. Pancreatic tumours are known to be extremely hypoxic and hypoxic stress selects for the establishment of more resistant cells presenting a more malignant genotype/phenotype [22]. Hypoxic insult also upregulates pro survival genes associated with stem cell maintenance and malignant progression [22-25]. Results from the qPCR analysis (Fig 7) revealed that chemosonodynamic therapy treatment caused a substantial reduction in the expression of HIF-1a and VHL suggesting that treated tumours were less hypoxic than untreated tumours. HIF-1 $\alpha$ is stable under hypoxic conditions and targets hypoxia responsive elements in target genes. However, when oxygen levels rise, hydroxylation of HIF-1a prolines occurs and recognition by VHL results in HIF-1 $\alpha$ degradation [26-28]. In addition, RUNX2 expression, which is known to possess pro-oncogenic functions and becomes elevated under hypoxic stress to help cancer cells survive, was also reduced in treated tumours relative to the untreated controls [29]. 
Increased expression of RUNX2 in tumours contributes to a more resistant aggressive phenotype by targeting genes associated with apoptosis, metastasis and angiogenesis [3033]. Furthermore, a substantial decrease was observed in the pro-angiogenic gene VEGFC for treated tumours indicating a decrease in endothelial cell recruitment that prevents the support of the tumour vasculature and this again confirms that the microenvironment in treated tumours was less hypoxic. Interleukin-8 (IL-8) gene mutations are found to be overexpressed in many pancreatic cell lines and again expression in treated tumours was $85 \%$ lower than in untreated tumours. Since this has also been shown to be play a significant role in angiogenesis and in particular, enhancing tumour endothelial cell survival and proliferation, its reduced expression in treated tumours could suggest therapeutic advantage [34]. Cancer stem cells (CSC) are a small population of cells that are involved in tumour initiation, growth, metastasis and resistance to therapy [35-38]. Survival of CSCs after treatment results in tumours becoming re-established and untreatable. Interestingly, chemo-sonodynamic therapy caused a significant reduction in two of the three CSC associated genes investigated (NANOG and EPCAM). NANOG has been positively identified in human pancreatic adenocarcinoma cells [39] and its expression was reduced by $60 \%$ in the treated tumours relative to the untreated controls. Similarly, a study carried out by Li et al [40] has shown that the CSC surface marker EPCAM is significantly over expressed in pancreatic cancer cells relative to non-tumourgenic cells and again its expression was reduced by $47 \%$ in treated tumours. It was interesting to note that whilst these two markers for stem cells were down-regulated, expression of another marker, SOX2, was slightly increased and this observation is the subject of ongoing investigations. Another interesting finding in our studies was the down regulation of SMAD4 in treated tumours. Interestingly, this is usually mutated in pancreatic cancer and since it is recognised as a tumour suppressor, its down regulation would have a positive impact on cancer progression [41]. However, it has also been reported that this gene is not mutated in MIA PaCa-2 cells and they are clearly tumorigenic [42]. Although the significance of it being down-regulated in our studies remains to be seen and although its role as a tumour suppressor is generally accepted, it is interesting to note that SMAD4 performs a tumour promoting role 
in hepatocellular carcinoma. [43] Nevertheless, in overall terms, the data from these studies strongly suggest that combined chemo-sonodynamic therapy produces beneficial reductions in the expression of several key genes implicated in the development and progression of pancreatic cancer.

Given the significant reduction in body weight observed for animals treated with Gem monotherapy (Fig 6b), and with a view for potential translation of UTMB mediated chemosonodynamic therapy to the clinic, we also undertook a safety study, as described in section 2.7, examining the effects of the treatment on key blood markers and organ histology, in nontumour bearing healthy MF1 mice. The mice were randomly allocated into four different groups with group 1 receiving no treatment, group 2 an $I V$ injection of the $O_{2} M B-G e m / O_{2} M B-R B$ suspension while groups 3 and 4 received an IV injection of Gem or RB respectively, at clinically scaled doses. Treatments were administered on days 0 and 7 with blood samples taken on day 15 for whole blood and serum biochemistry analysis after which the animals were euthanised. The liver and kidneys were then removed for histological examination. Both Gem and RB have safely been used in humans before and therefore possess acceptable toxicology profiles. The aim of this experiment, therefore, was to ensure the toxicity of MB delivered Gem and RB was no worse than the free drugs alone. Naturally, as the concentrations of Gem and RB used as part of the MB formulation are less than their normal systemic dose, one would expect this to be the case. However, it is prudent to rule out any potential deleterious interaction between the $\mathrm{MB}$ and bound drugs. The results from this analysis are shown in Fig 8 and reveal no major differences in the levels of key blood markers for any the groups tested with only minor changes observed for ALT, platelet and neutrophil levels. Elevated ALT levels are an indicator of liver damage while reduced platelet and neutrophil levels are commonly observed following chemotherapy treatment [44-45]. While the platelet and neutrophil levels were slightly lower in animals treated with $\mathrm{O}_{2} \mathrm{MB}-\mathrm{Gem} / \mathrm{O}_{2} \mathrm{MB}$ RB compared to untreated animals, the magnitude of these changes were smaller than for free Gem or RB. Surprisingly, the ALT level observed for the $\mathrm{O}_{2} \mathrm{MB}-\mathrm{Gem} / \mathrm{O}_{2} \mathrm{MB}-\mathrm{RB}$ group 
was lower than the control but both were lower than free Gem or RB. The reason for the reduced $A L T$ level in the $\mathrm{O}_{2} \mathrm{MB}-\mathrm{Gem} / \mathrm{O}_{2} \mathrm{MB}-\mathrm{RB}$ group compared to untreated animals was surprising but this is not as concerning when compared to an elevated ALT level. However, the results from the blood analysis do not raise any concerns as to the safety of the $\mathrm{O}_{2} \mathrm{MB}$ Gem / $\mathrm{O}_{2}$ MB-RB formulation. Similarly, histological analysis of liver and kidney sections also revealed no noteworthy changes between groups $2-4$, although there was a slight increase in hepatic lobular inflammation and steatosis for these groups relative to the untreated group. Analysis of kidney sections showed slightly raised levels of tubular vacuolation for the $\mathrm{O}_{2} \mathrm{MB}$ Gem / $\mathrm{O}_{2} \mathrm{MB}-\mathrm{RB}$ group, but again these levels were raised in the Gem and RB groups and the differences were non-significant. It must be stressed, however, that any effect observed in the liver or kidney histology analysis was deemed to be mild and in no case did the mean score exceed 2. Collectively, these results indicate the potential of $\mathrm{O}_{2} \mathrm{MB}$ as a safe and effective platform for the delivery of combined antimetabolite and SDT treatment of pancreatic cancer.

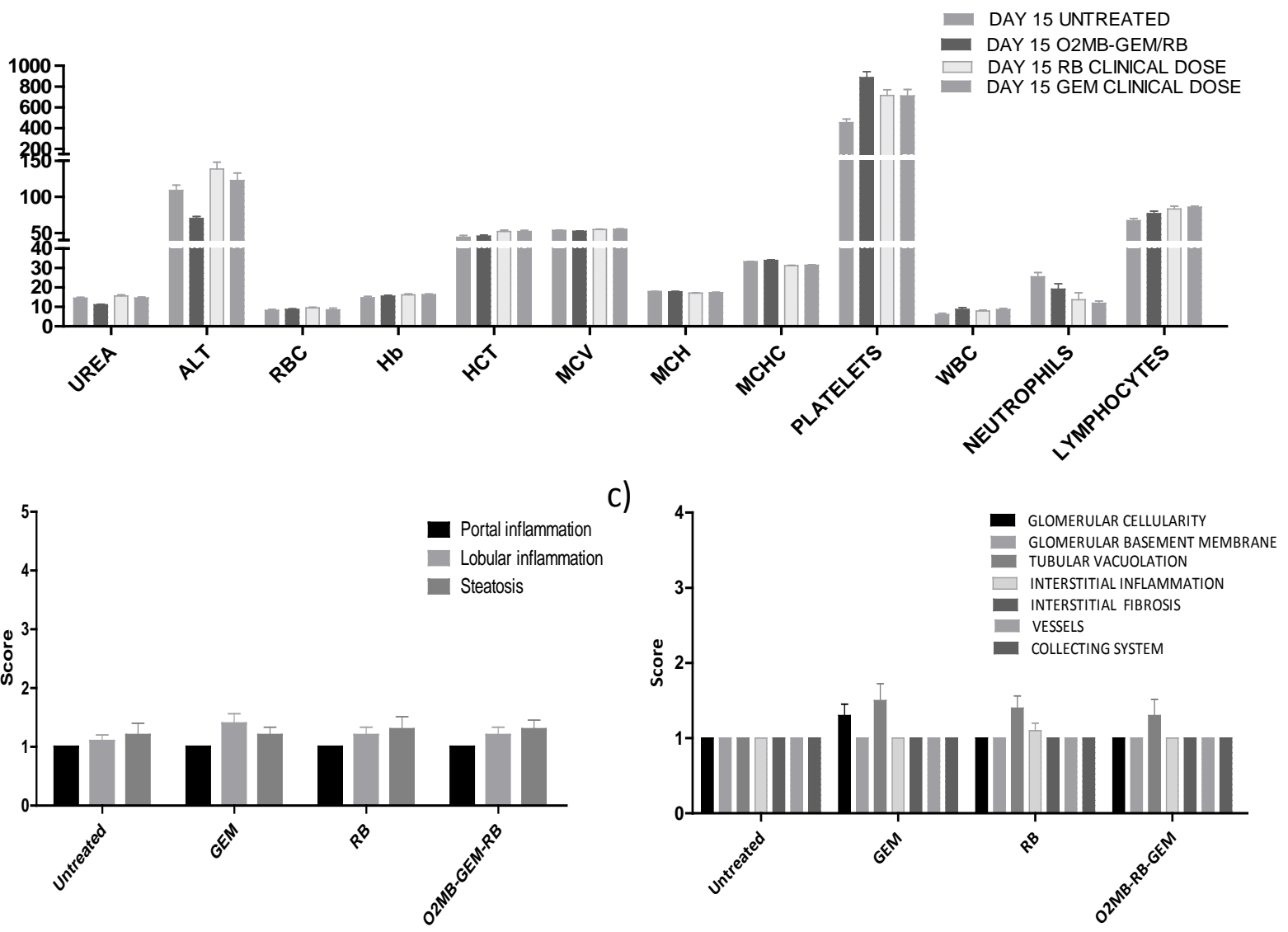


Figure 8 (a) Blood haematology and histology analysis, (b) liver histology, and (c) kidney histology analyses for MF-1 mice at day 15 following initial treatment with Gem, RB or the $\mathrm{O}_{2} \mathrm{MB}-\mathrm{Gem} / \mathrm{O}_{2} \mathrm{MB}-\mathrm{RB}$ conjugate. Untreated mice were used as a control group.

4.0 Conclusion: In conclusion, the results presented above demonstrate that UTMD is an effective method to deliver chemo-sonodynamic therapy to pancreatic tumours. In addition, the efficacy of chemo-sonodynamic therapy was significantly better than conventional Gem monotherapy at concentrations that were 240-fold lower. UTMD mediated chemosonodynamic therapy was also extremely well tolerated with no observable acute toxicity and no change to key blood biochemical markers or liver / kidney histology. The treatment also caused a reduction in the expression of genetic markers associated with the progression of pancreatic cancer such as HIF-1 $\alpha$, VHL, VEGFC, IL8, NANOG and EPCAM. Given the lack of improvement in pancreatic cancer survival over the past four decades there is a clear unmet need for new treatments with improved efficacy and reduced off target toxicity. We believe that UTMD mediated chemo-sonodynamic therapy offers significant potential for the treatment of pancreatic cancer and are actively developing the technology for clinical translation.

Acknowledgements: The authors acknowledge Invest NI for funding. JFC thanks Norbrook Laboratories Ltd for an endowed chair. KL thanks Department for the Economy (DfE) in Northern Ireland for a PhD studentship. 


\section{References}

[1] Transparency Market Research. https://www.transparencymarketresearch.com/pancreaticcancer-market.html, accessed (11 November 2017).

[2] H. Tajima, I. Makino, Y. Ohbatake, S. Nakanuma, H. Hayashi, H. Nakagawara, T. Miyashita, H. Takamura, T. Ohta, "Neoadjuvant chemotherapy for pancreatic cancer: Effects on cancer tissue and novel perspectives" Oncology Lett. 13 (2017) 3975-3981.

[3] A. Mitra, B. Sirohi, S.V. Shrikhande, Neoadjuvant therapy in pancreatic cancer, Current Medicine Research and Practice. 4 (2014) 56-61.

[4] A. Wang-Gillam, C. Li, G. Bodoky, A. Dean, Y. Shan, G. Jameson, T. Macarulla, K. Lee, D. Cunningham, J.F. Blanc, Nanoliposomal irinotecan with fluorouracil and folinic acid in metastatic pancreatic cancer after previous gemcitabine-based therapy (NAPOLI-1): a global, randomised, open-label, phase 3 trial, The Lancet. 387 (2016) 545-557.

[5] G. Ouyang, Z. Liu, S. Huang, Q. Li, L. Xiong, X. Miao, Y. Wen, Gemcitabine plus cisplatin versus gemcitabine alone in the treatment of pancreatic cancer: a meta-analysis, World journal of surgical oncology. 14 (2016) 59.

[6] C. Fan, C. Ting, H. Liu, C. Huang, H. Hsieh, T. Yen, K. Wei, C. Yeh, Antiangiogenic-targeting drug-loaded microbubbles combined with focused ultrasound for glioma treatment, Biomaterials. 34 (2013) 2142-2155.

[7] A. Liao, Y. Li, W. Lee, M. Wu, H. Liu, M. Kuo, Estimating the delivery efficiency of drug-loaded microbubbles in cancer cells with ultrasound and bioluminescence imaging, Ultrasound Med. Biol. 38 (2012) 1938-1948.

[8] L. Xing, Q. Shi, K. Zheng, M. Shen, J. Ma, F. Li, Y. Liu, L. Lin, W. Tu, Y. Duan, Ultrasoundmediated microbubble destruction (UMMD) facilitates the delivery of CA19-9 targeted and paclitaxel loaded mPEG-PLGA-PLL nanoparticles in pancreatic cancer, Theranostics. 6 (2016) 1573.

[9] R. Carlisle, J. Choi, M. Bazan-Peregrino, R. Laga, V. Subr, L. Kostka, K. Ulbrich, C-C. Coussios, L.W. Seymour., "Enhanced Tumor Uptake and Penetration of Virotherapy Using Polymer Stealthing and Focused Ultrasound" J NCl, 105, (2013) 1701-1710.

[10] G. Dimcevski, S. Kotopoulis, T. Bjånes, D. Jan Schjøtt, B.T. Gjertsen, M. Biermann, A. Molven, H. Sorbye, E.McCormack, M. Postema, O.H. Gilja, "A human clinical trial using ultrasound and microbubbles to enhance gemcitabine treatment of inoperable pancreatic cancer". Journal of Controlled Release 243 (2016) 172-181.

[11] C. McEwan, J. Owen, E. Stride, C. Fowley, H. Nesbitt, D. Cochrane, C.C. Coussios, M. Borden, N. Nomikou, A.P. McHale, Oxygen carrying microbubbles for enhanced sonodynamic therapy of hypoxic tumours, J. Controlled Release. 203 (2015) 51-56.

[12] C. McEwan, S. Kamila, J. Owen, H. Nesbitt, B. Callan, M. Borden, N. Nomikou, R.A. Hamoudi, M.A. Taylor, E. Stride, Combined sonodynamic and antimetabolite therapy for the improved treatment of pancreatic cancer using oxygen loaded microbubbles as a delivery vehicle, Biomaterials. 80 (2016) 20-32.

[13] G. Wan, Y. Liu, B. Chen, Y. Liu, Y. Wang, N. Zhang, Recent advances of sonodynamic therapy in cancer treatment, Cancer biology \& medicine. 13 (2016) 325.

[14] S.R. Hingorani, L. Wang, A.S. Multani, C. Combs, T.B. Deramaudt, R.H. Hruban, A.K. Rustgi, S. Chang, D.A. Tuveson, Trp53R172H and KrasG12D cooperate to promote chromosomal instability and widely metastatic pancreatic ductal adenocarcinoma in mice, Cancer cell. 7 (2005) 469-483. 
[15] Invitrogen TRIzol Reagent $\quad$ Guide. https://tools.thermofisher.com/content/sfs/manuals/trizol_reagent.pdf, 2016 (accessed 11 Novemebr 2017).

[16] Roche, Transcriptor First Strand cDNA Synthesis Kit. http://facstaff. bloomu.edu/gdavis/MoBio/Transcriptor\%20full\%20manual.pdf, 2006 (accessed 11 November 2017).

[17] K. Ishak, A. Baptista, L. Bianchi, F. Callea, J. De Groote, F. Gudat, H. Denk, V. Desmet, G. Korb, R.N. MacSween, Histological grading and staging of chronic hepatitis, J. Hepatol. 22 (1995) 696-699.

[18] D.E. Kleiner, E.M. Brunt, M. Van Natta, C. Behling, M.J. Contos, O.W. Cummings, L.D. Ferrell, Y. Liu, M.S. Torbenson, A. Unalp-Arida, Design and validation of a histological scoring system for nonalcoholic fatty liver disease, Hepatology. 41 (2005) 1313-1321.

[19] M. Elnaggar, E. Giovannetti, G. J Peters, Molecular targets of gemcitabine action: rationale for development of novel drugs and drug combinations, Curr. Pharm. Des. 18 (2012) 2811-2829.

[20] H. Han, H. Wang, Y. Chen, Z. Li, Y. Wang, Q. Jin, J. Ji, Theranostic reduction-sensitive gemcitabine prodrug micelles for near-infrared imaging and pancreatic cancer therapy, Nanoscale. 8 (2016) 283-291.

[21] J.W. Wojtkowiak, H.C. Cornnell, S. Matsumoto, K. Saito, Y. Takakusagi, P. Dutta, M. Kim, X. Zhang, R. Leos, K.M. Bailey, Pyruvate sensitizes pancreatic tumors to hypoxia-activated prodrug TH302, Cancer \& metabolism. 3 (2015) 2.

[22] N. Byrne, H. Nesbitt, L. Ming, S. McKeown, J. Worthington, D. McKenna, Androgen deprivation in LNCaP prostate tumour xenografts induces vascular changes and hypoxic stress, resulting in promotion of epithelial-to-mesenchymal transition, Br. J. Cancer. 114 (2016) 659-668.

[23] A.E. Greijer, E. van der Wall, The role of hypoxia inducible factor 1 (HIF-1) in hypoxia induced apoptosis, J. Clin. Pathol. 57 (2004) 1009-1014.

[24] Z. Li, J.N. Rich, Hypoxia and hypoxia inducible factors in cancer stem cell maintenance, in: Anonymous Diverse Effects of Hypoxia on Tumor Progression, Springer, 2010, pp. 21-30.

[25] Y. Tsai, K. Wu, Hypoxia-regulated target genes implicated in tumor metastasis, J. Biomed. Sci. 19 (2012) 102.

[26] D.P. Stiehl, R. Wirthner, J. Koditz, P. Spielmann, G. Camenisch, R.H. Wenger, Increased prolyl 4-hydroxylase domain proteins compensate for decreased oxygen levels. Evidence for an autoregulatory oxygen-sensing system, J. Biol. Chem. 281 (2006) 23482-23491.

[27] M. ER, The tumor suppressor protein VHL targets hypoxia-inducible factors for oxygendependent proteolysis, Nature. 399 (1999) 271-275.

[28] K. Kondo, J. KIco, E. Nakamura, M. Lechpammer, W.G. Kaelin, Inhibition of HIF is necessary for tumor suppression by the von Hippel-Lindau protein, Cancer cell. 1 (2002) 237-246.

[29] F. Otto, A.P. Thornell, T. Crompton, A. Denzel, K.C. Gilmour, I.R. Rosewell, G.W. Stamp, R.S. Beddington, S. Mundlos, B.R. Olsen, Cbfa1, a candidate gene for cleidocranial dysplasia syndrome, is essential for osteoblast differentiation and bone development, Cell. 89 (1997) 765-771.

[30] J. Pratap, A. Javed, L.R. Languino, A.J . van Wijnen, J.L. Stein, G.S. Stein, J.B. Lian, The Runx2 osteogenic transcription factor regulates matrix metalloproteinase 9 in bone metastatic cancer cells and controls cell invasion, Mol. Cell. Biol. 25 (2005) 8581-8591. 
[31] G. Browne, H. Nesbitt, L. Ming, G.S. Stein, J.B. Lian, S.R. McKeown, J. Worthington, Bicalutamide-induced hypoxia potentiates RUNX2-mediated $\mathrm{BCl}-2$ expression resulting in apoptosis resistance, Br. J. Cancer. 107 (2012) 1714-1721.

[32] H. Nesbitt, G. Browne, K.M. O'Donovan, N.M. Byrne, J. Worthington, S.R. McKeown, D.J. McKenna, Nitric Oxide Up-Regulates RUNX2 in LNCaP Prostate Tumours: Implications for Tumour Growth In Vitro and In Vivo, J. Cell. Physiol. 231 (2016) 473-482.

[33] E. Zelzer, D.J . Glotzer, C. Hartmann, D. Thomas, N. Fukai, S. Soker, B.R. Olsen, Tissue specific regulation of VEGF expression during bone development requires Cbfal/Runx2, Mech. Dev. 106 (2001) 97-106.

[34] A. Li, S. Dubey, M.L. Varney, B.J. Dave, R.K. Singh, IL-8 directly enhanced endothelial cell survival, proliferation, and matrix metalloproteinases production and regulated angiogenesis, J. Immunol. 170 (2003) 3369-3376.

[35] Y. Ohara, T. Oda, M. Sugano, S. Hashimoto, T. Enomoto, K. Yamada, Y. Akashi, R. Miyamoto, A. Kobayashi, K. Fukunaga, Histological and prognostic importance of CD44/CD24 /EpCAM expression in clinical pancreatic cancer, Cancer science. 104 (2013) 1127-1134.

[36] A. Mohammed, N.B. Janakiram, M. Brewer, R.L. Ritchie, A. Marya, S. Lightfoot, V.E. Steele, C.V. Rao, Antidiabetic drug metformin prevents progression of pancreatic cancer by targeting in part cancer stem cells and mTOR signaling, Translational oncology. 6 (2013) 649IN7-659.

[37] S.M. Sureban, R. May, S.A. Lightfoot, A.B. Hoskins, M. Lerner, D.J. Brackett, R.G. Postier, R. Ramanujam, A. Mohammed, C.V. Rao, J.H. Wyche, S. Anant, C.W. Houchen, DCAMKL-1 regulates epithelial-mesenchymal transition in human pancreatic cells through a miR-200a-dependent mechanism, Cancer Res. 71 (2011) 2328-2338.

[38] L. Li, L. Borodyansky, Y. Yang, Genomic instability en route to and from cancer stem cells, Cell Cycle. 8 (2009) 1000-1002.

[39] Z. Zhang, Q. Duan, H. Zhao, T. Liu, H. Wu, Q. Shen, C. Wang, T. Ying. Gemcitabine treatment promotes pancreatic cancer stemness through the Nox/ROS/NF/STAT3 signaling cascade. Cancer Lett. 382 (2016) 53-63.

[40] C. Li, D.G. Heidt, P. Dalerba, C.F. Burant, L. Zhang, V. Adsay, M. Wicha, M.F. Clarke, D.M. Simeone, Identification of pancreatic cancer stem cells, Cancer Res. 67 (2007) 1030-1037.

[41] J . Cicenas, K. Kvederaviciute, I. Meskinyte, E. Meskinyte-Kausiliene, A. Skeberdyte, J . Cicenas, KRAS, TP53, CDKN2A, SMAD4, BRCA1, and BRCA2 Mutations in Pancreatic Cancer, Cancers. 9 (2017) 42.

[42] E.Deer, J. Gonzalez-Hernandez, J.D. Coursen, J.E. Shea, J. Ngatia, C.L. Scaife, M.A. Firpo, S.J. Mulvihill. Phenotype and genotype of pancreatic cancer cell lines. Pancreas. 39 (2010) 425-435.

[43] P.Y. Hernanda, K. Chen, A. Das, K. Sideras, W. Wang, J. Li, W. Cao, S. Bots, L. L. Kodach, R. De Man, SMAD4 exerts a tumor-promoting role in hepatocellular carcinoma, Oncogene. 34 (2015) 5055-5068.

[44] W. Kim, S.L. Flamm, A.M. Di Bisceglie, H.C. Bodenheimer, Serum activity of alanine aminotransferase (ALT) as an indicator of health and disease, Hepatology. 47 (2008) 1363-1370.

[45] Cancer Treatment Centers of America. http://www.cancercenter.com/community/managingside-effects/blood-counts/ , 2017 (accessed 11 October 2017). 
